\title{
FIRST ISOLATION OF MYCOBACTERIUM AVIUM SUBSP PARATUBERCULOSIS FROM COMMERCIAL PASTEURIZED MILK IN ARGENTINA
}

\author{
Fernando Paolicchi* ${ }^{1,2}$; Karina Cirone ${ }^{1,2}$; Claudia Morsella ${ }^{1}$; Andrea Gioffré ${ }^{3}$ \\ ${ }^{1}$ Laboratory of Bacteriology, INTA, Argentina, ${ }^{2}$ School of Agricultural Sciences, National University of Mar del Plata, \\ ${ }^{3}$ Institute of Biotechnology, INTA, Castelar.
}

Submitted: July 18, 2011; Returned to authors for corrections: September 25, 2011; Approved: June 07, 2012.

\begin{abstract}
Mycobacterium avium subsp paratuberculosis was isolated from two out of seventy samples (2.86 \%) of pasteurized and ultra-pasteurized milk. The isolates were positives to IS900 PCR and showed a C17 RFLP pattern, the most prevalent in Argentina. The present study is the first report of Mycobacterium avium subsp paratuberculosis culture from pasteurized milk in Argentina.
\end{abstract}

Key words: Paratuberculosis, Mycobacterium avium subsp paratuberculosis, pasteurized milk, PCR IS900

Mycobacterium avium subsp. paratuberculosis $(M A P)$ is the causative agent of Paratuberculosis (PTB). It affects domestic and wild animals causing chronic enteritis producing diarrhea, weight loss, and progressive emaciation that can lead to death (3). MAP has been also linked to human Crohn's disease, a disorder that causes mainly a chronic inflammation of the intestine (12). In the last ten years, there has been important progress in the research of the relationship between this microorganism and Crohn's disease. This research has focused mainly on food products as the transmission pathway and $M A P$ has been considered as a possible zoonotic microorganism (18).

The way in which $M A P$ is transmitted is not fully understood yet, but some evidence suggest that humans can get infected through contaminated milk. Some authors suggest that pasteurization is capable of destroying mycobacteria. Stabel (24) have shown that when milk is inoculated with MAP and subjected to a treatment of $65^{\circ} \mathrm{C}$ for $30 \mathrm{~min}, M A P$ are killed since no viable microorganisms were found after 28 days of incubation. Likewise, Pearce et al. (21) stated that the commercial pasteurization provides an effective inactivation of $M A P$. In contrast, other authors support the theory that when $M A P$ is present in milk, it is able to resist the pasteurization conditions $(5,6,9,10)$.

In the United Kingdom, viable MAP was detected in $1.7 \%$ of samples of commercial pasteurized milk (7) and in $6.7 \%$ of samples of naturally infected raw milk subjected to commercial scale pasteurization at $72^{\circ} \mathrm{C}$ for 15 or $25 \mathrm{~s}(8)$. In the United States, viable organisms were found in a small number of bottles of commercial pasteurized milk in California, Minnesota and Wisconsin (2.8\% of the 702 samples analyzed contained viable $M A P$ ) (4). In the Czech Republic, M. avium was cultured from 4 of $244(1.6 \%)$ units of commercially pasteurized retail milk (1). In other studies, powdered infant milk from seven countries were tested, and DNA MAP IS900 was detected in $49 \%$ of the samples, whereas using real time

*Corresponding Author. Mailing address: EEA INTA, Department of Animal Production, CC 276, Balcarce (7620) Argentina.; E-mail: fpaolicchi@balcarce.inta.gov.ar 
PCR the sequence f57 was detected in 35\% of them (14). Additionally, samples positive by culture showed viable $M A P$ in powered infant formula (13). In India, the presence of $M A P$ was evaluated in 43 samples of pasteurized and unpasteurized commercial milk, and viable $M A P$ was isolated from $67 \%$ of the pasteurized milk samples and $44 \%$ of the unpasteurized milk samples, and $6 \%$ and $33 \%$ were found to be positive for DNA MAP IS900 (22).

These results indicate that this pathogen is occasionally capable of surviving commercial pasteurization. MAP could also be present in cheese and other products elaborated with non-pasteurized milk such as goat's milk, which is frequently consumed without pasteurization. In Argentina, the viability of $M A P$ was evaluated during maturity in cheeses with a $37^{\circ} \mathrm{C}$ heat treatment of milk, and it was found that $M A P$ can remain viable until 60 and 45 days post-maturation in goat and bovine cheeses infected with $M A P$ in milk, respectively (2). Because the prevalence of PTB in dairy cattle in Argentina is high, we hypothesized that is possible to find viable $M A P$ in commercial milk. The objective of the present work was to identify the presence of viable $M A P$ in commercial pasteurized milk.

One-liter bottles of commercial fluid milk were purchased at random in supermarkets located southeast of the Province of Buenos Aires, Argentina, over seven months (from June to December). A total of 70 samples of commercial milk (18 pasteurized, 30 ultra pasteurized and 22 ultrapasteurized at high temperature) were cultured to identify Mycobacterium avium subsp. paratuberculosis. The samples were classified as high quality (first trademark $n=14$ ) and low quality (second trademark, $\mathrm{n}=56$ ).

An aliquot of $50 \mathrm{ml}$ of milk was taken from each sample, transferred to sterile plastic tubes and centrifuged at $2500 \mathrm{~g}$ for $30 \mathrm{~min}$, to obtain a pellet and cream fraction. The samples were not decontaminated because they may have contained minor contaminant microorganisms. Negative samples and positive controls infected with viable $M A P$ were included in all the procedures.
The pellet and cream fraction were re-suspended in $25 \mathrm{ml}$ of sterile saline buffer $\mathrm{pH} 7.0$ (PBS), agitated until complete dissolution, and then kept at room temperature overnight. They were then centrifuged at $2000 \mathrm{~g}$ for $30 \mathrm{~min}, 1 \mathrm{ml}$ brainheart broth was added to each pellet and cream fraction, and then kept at $37^{\circ} \mathrm{C}$ overnight. An aliquot of $120 \mu \mathrm{l}$ was cultured in triplicate on Herrold's medium, Herrold plus mycobactin and pyruvate (HMP), and HMP plus antibiotics (HMPA), as previously described (19). The cultures were observed every 15 days for four months, and the colonies suspected of presenting $M A P$ development were identified by morphology and Ziehl Neelsen staining.

For identification of mycobacterial isolates all colonies were processed by PCR and restriction enzyme analysis of IS1311 to distinguish this insertion sequence, which is common to the M. avium complex. Additionally, two $\mathrm{ml}$ of each strain were taken from the culture medium, and kept at $37^{\circ} \mathrm{C}$ to extract DNA and to perform analysis of IS900. The extracted DNA was amplified in a reaction mixture containing: $2.5 \mu \mathrm{l}$ of each primer IS900 (50 ng/ $\mu \mathrm{l})$, P90 5', (GAAGGGTGTtCGGGGCCGTC) and P91 (GAGGTCGA TCGCCCACGTGAC) (15), $5 \mu \mathrm{l}$ of the buffer $10 \mathrm{X}(200 \mathrm{mM}$ Tris $\mathrm{HCl} \mathrm{pH} \mathrm{8.4,} 500 \mathrm{mM} \mathrm{KCl}$ and $50 \mathrm{mM} \mathrm{MgCl} 2), 4 \mu \mathrm{dNTP}$ mix (2.5 mM of each dNTP), and $0.25 \mu$ of Taq polymerase ( 5 units/ $\mu \mathrm{l}$ ) per reaction. Each sample was homogenized and transferred to a tube of PCR in aliquots of $20 \mu \mathrm{l}$. Each mixture was covered with mineral oil and subjected to amplification. The samples were subjected to protocol: 25 cycles at $94^{\circ} \mathrm{C}$ for $3 \mathrm{~min}, 94^{\circ} \mathrm{C}$ for $1 \mathrm{~min}, 65^{\circ} \mathrm{C}$ for $1 \mathrm{~min}$ and to $72^{\circ} \mathrm{C}$ for $2 \mathrm{~min}$; and to one cycle at $72^{\circ} \mathrm{C}$ for $4 \mathrm{~min}$. For each set of PCRs, both a positive (DNA of MAP reference strains) and a negative control (sterile distilled water) were used. An aliquot of each amplification mixture was subjected to electrophoresis in agarose gel at $2 \%$ with Tris-borate buffer EDTA (TBE; 89 $\mathrm{mM}$ Tris, $1 \mathrm{mM}$ boric acid, $2 \mathrm{mM}$ EDTA). The DNA bands were observed under UV light after ethidium bromide staining. The samples were classified as positive when the band size 
(400 bp) was identified in gel. The strains were typed by RFLP methods using the restriction endonuclease BstEll, and the RLFP- IS900 of MAP type isolated were classified using patterns A (RC17), B, C or E of RFLP $(17,20)$.

From all the milk samples analyzed, $2.86 \%$ were culturepositive and the colonies cultured on HMP and HMPA presented the typical morphology and Ziehl Neelsen-positive stains. $M A P$ was identified after 8 weeks in one sample of pasteurized milk and in one sample of milk ultra-pasteurized at high temperature in second trade make. In the primary isolation, a few colonies $(n=5-10)$ were recovered but the colonies were positive for the IS900 PCR. The genetic identification in the $M A P$ strains isolated here from commercial milk revealed that they belong to pattern " $\mathrm{A}$ " (RC17 European type), which is the most prevalent one in Argentina, as we have demonstrated previously (17).

Slana et al. (23) reported the different methods used for detection of $M A P$ in milk and milk products and analyzed the current methods for direct or non-direct identification of $M A P$ that can be applied to milk and milk products. The gold standard testing method for $M A P$ infection is culture, but there are other faster, more sensitive and specific molecular biology methods for the detection of the bacelli such as PCR $(15,16)$ and the search for restriction fragment length polymorphism (RFLP). These analyses are based on the identification of IS900, an insertion sequence that appears to belong only to $M A P(11)$.

We have previously analyzed the seroprevalence of PTB in dairy and meat cattle in Argentina, and found prevalence between $7.2 \%$ and $19.6 \%$ in ELISA (19), in the same area where the commercial milks used in this work were obtained. We demonstrate that it is possible to identify viable $M A P$ from commercial pasteurized milk obtained from dairy herds presumably infected with PTB. This indicates that $M A P$ can resist inactivation by heat treatments to which milk is subjected before commercialization and consumption. Although the number of milk bottles examined in this work was small, the positive samples found represent $2.86 \%$ of all samples tested and these results are in agreement with that found by different authors in other countries $(1,4,8,22)$. Studies performed in the United Kingdom revealed that $M A P$ is present in $1.7 \%$ of samples of commercial pasteurized milk (17).

This finding is the first reported of its kind in Argentina from commercial milk and indicates the risk of population infection usually consuming this product. On the other hand, one possible explanation for the presence of $M A P$ in commercial milk could be post-pasteurization contamination. If raw milk containing $M A P$ is brought into a processing plant and sanitation methods are not adequate, MAP could be present in the environment and contaminate the final product $(4,7)$. In the USA and Europe, MAP has been cultured from chlorinated potable municipal water, pasteurized milk, the intestine and stools from patients with Crohn's disease, breast milk from mothers with Crohn's disease, and blood from patients with Inflammatory Bowel Disease. These findings reinforce the concept of zoonosis and the possible link between MAP-contaminated food and Crohn's disease. The results obtained in this work emphasize the importance of improving the controls in dairy farms and in the milk industry with the aim to protect consumers from the risk of infection with $M A P$. Further qualitative and quantitative research is still necessary to clarify the role of $M A P$ resistance to heat treatments performed in the milk industry, as well as to evaluate its survival to the different elaboration processes used for dairy products. Also, fast, reliable and inexpensive detection methods of MAP should be developed so that efficient control measures could be later applied in primary milk production and manufacture or processing of milk food.

\section{REFERENCES}

1. Ayele, W.; Svastova, P.; Roubal, P.; Bartos, M.; Pavlik, I. (2005). Mycobacterium avium subsp. paratuberculosis cultured from locally and commercially pasteurized cow's milk in the Czech Republic. Appl. 
Environ. Microbiol. 71, 1210-1214.

2. Cirone, K. (2004). Characterization and viability of Mycobacterium avium subsp. paratuberculosis in milk, cheese and water. Balcarce, Argentina, 65p. Thesis of Graduate. Faculty of Agrarian Sciences, Universidad Nacional de Mar del Plata, Argentina.

3. Collins, M.; Goodger, W.; Nordlund, K.; Pelletier, J. (1996). Associations between subclinical paratuberculosis and milk production, milk components, and somatic cell counts in dairy herds. J. Am. Vet. Med. Assoc. 208, 1872-1876.

4. Ellingson, J.; Anderson, J.; Koziczkowski, J.; Radcliff, R.; Sloan, S.; Allen, S.; Sullivan, N. (2005). Detection of viable Mycobacterium avium subsp. paratuberculosis in retail pasteurized whole milk by two culture methods and PCR. J. Food Prot. 68, 966-972.

5. Grant, I.; Ball, H.; Rowe, M. (1999). Effect of higher pasteurization temperatures and longer holding times at 72 degrees $\mathrm{C}$, on the inactivation of Mycobacterium avium subsp. paratuberculosis in milk. Lett. Appl. Microbiol. 28, 461-465.

6. Grant, I.; Pope, C.; O'Riordan, L.; Ball, H.; Rowe, M. (2000). Improved detection of Mycobacterium avium subsp. paratuberculosis in milk by immunomagnetic PCR. J. Vet. Microbiol. 77, 369-378.

7. Grant, I.; Hitchings, E.; Ball, H.; Rowe, M. (2002a). Impact of commercial HTST pasteurization on Mycobacterium avium subsp. paratuberculosis in naturally infected cow's milk. Appl. Environ. Microbiol. 68, 602-607.

8. Grant, I.; Ball, H.; Rowe, M. (2002b). Incidence of Mycobacterium avium subsp. paratuberculosis in bulk raw and commercial pasteurized cow's milk from approved dairy processing establishments in the United Kingdom. Appl. Envirom. Microbiol. 68, 2428-2435.

9. Grant, I.; Kirk, E.; Hitchings, E.; Rowe, M. (2003). Comparative evaluation of MGIT and BACTEC culture systems for the recovery of Mycobacterium avium subsp. paratuberculosis from milk. J. Appl. Microbiol. 95, 169-201.

10. Grant, I. (2006). Occurrence of Mycobacterium avium subsp paratuberculosis in foods and the impact of milk processing on its survival. $8^{\text {th }}$ Int. Colloquium on Paratuberculosis, Copenhague, Denmark. p. 276

11. Green, G.; Tizard, M.; Thompson, J.; Winterbourme, D.; Mc Fadden, J.; Hermon-Taylor, J. (1989). Sequence and characteristic of IS900, and insertion sequence identified in human Crohn's disease isolate of Mycobacterium avium subsp. paratuberculosis. Nucleic Acid Res. 17, 9063-9073.

12. Hermon-Taylor, J. (2002). Mycobacterium avium subsp. paratuberculosis and its relation to Crohn's disease. $7^{\text {th }}$ Int. Colloquium on Paratuberculosis. Bilbao, Spain, p. 96

13. Hruska, K.; Bartos, M.; Kralik, P.; Pavlik, I. (2005). Mycobacterium avium subsp. paratuberculosis in powdered infant milk: paratuberculosis in cattle - the public health problem to be solved. Vet. Med. Czech. 50,
327-335.

14. Hruska, K.; Slana, I.; Kralik, P.; Pavlik, I. (2011). Mycobacterium avium subsp. paratuberculosis in powdered infant milk: F57 competitive real time PCR. Vet. Med. Czech. 56, 226-230.

15. Khare, S.; Fitch, T.; Santos, R.; Romano, J.; Fitch, A.; Zhang, S.; Grant, I.; Libal, M.; Hunter, D.; Adams, G. (2004). Rapid and sensitive detection of Mycobacterium avium subsp. paratuberculosis in bovine milk and feces by combination of immunomagnetic bead separationconventional PCR and real-time PCR. J. Clinical Microbiol. 42, 10751081.

16. Millar, D.; Ford, J.; Withey, S.; Tizard, M.; Doran, T.; Hermon-Taylor, J. (1996) IS900 PCR to detect Mycobacterium avium subsp. paratuberculosis in retail supplies of whole pasteurized cow's milk in England en Wales. Appl. Environ. Microbiol. 5, 2446-2452.

17. Moreira, A.; Paolicchi, F.; Morsella, C.; Zumarraga, M.; Cataldi, A.; Bigi, F.; Alito, A.; Overduin, P.; van Soolingen, D.; Romano, M. (1999). Distribution of IS900 restriction length polymorphism types among animal Mycobacterium avium subsp. paratuberculosis isolates from Argentina and Europe. J. Vet. Microbiol. 70, 251-259.

18. Naser, S.; Schwarzt, D.; Shafran, I. (2000). Isolation of Mycobacterium avium subsp. paratuberculosis from breast milk of Crohn's disease patients. Am. J. Gastroenterol. 95,1094-1095.

19. Paolicchi, F.; Zumárraga, M.; Gioffre, A.; Zamorano, P.; Morsella, C.; Verna, A.; Cataldi, A.; Alito, A.; Romano, M. (2003). Application of different methods for the diagnosis of paratuberculosis in dairy cattle herds in Argentina. J. Vet. Med. 50, 20-26.

20. Pavlik, I. ; Horvathova, A. ; Dvoska, L. ; Svastova, P. ; du Maine, R. ; Fixa, B.; Rychlik, I. (1999). Homogeneity/Heterogeneity of Mycobacterium avium subsp. paratuberculosis strains. Correlation between RFLP-Type and source (animal, enviromental, human). $6^{\text {th }}$ Int. Colloquium on Paratuberculosis. Australia, p. 321-329.

21. Pearce, E.; Crawford, R.; Troung, H.; Yates, G.; Lisle, G. (2002). The recovery of Mycobacterium avium subsp. paratuberculosis following heat treatment of inoculated milk in a turbulent-flow pasteurizer is not adversely affected by decontamination and antibiotic selection. $7^{\text {th }}$ Int. Colloquium on Paratuberculosis. Bilbao, Portugal; p. 102.

22. Shankar, H.; Singh, S.; Singh, P.; Singh, A.; Sohal, J.; Greenstein, R. (2009). Presence, characterization and genotype profiles of Mycobacterium avium subsp. paratuberculosis from unpasteurized individual and pooled milk, commercial pasteurized milk and milk production products in India by culture, PCR and PCR REA methods. Int. J. Infect. Dis. 14(2), 121-126.

23. Slana, I.; Paolicchi, F.; Janstova, B.; Navratilova, P.; Pavlík, I. (2008). Detection methods for Mycobacterium avium subsp. paratuberculosis in milk and milk products: a review. Vet. Med. Czech. 53, 286-306.

24. Stabel, J. (2001). On-farm batch pasteurization destroys Mycobacterium avium subsp. paratuberculosis in waste milk. J. Dairy Sci. 84, 524-527. 